\title{
The On-Orbit Calibration of SeaWiFS: Revised Temperature and Gain Corrections
}

\author{
Robert E. Eplee, Jr., ${ }^{a}$ Frederick S. Patt, ${ }^{a}$ Gerhard Meister, ${ }^{b}$ \\ Bryan A. Franz, ${ }^{a}$ Sean W. Bailey, ${ }^{b}$ and Charles R. McClain ${ }^{c}$ \\ ${ }^{a}$ Science Applications International Corporation, Beltsville, Maryland 20705, USA \\ ${ }^{b}$ Futuretech Corporation, Greenbelt, Maryland 20770, USA \\ ${ }^{c}$ NASA Goddard Space Flight Center, Greenbelt, Maryland 20771, USA
}

\begin{abstract}
The NASA Ocean Biology Processing Group's Calibration and Validation (Cal/Val) Team has used SeaWiFS onorbit lunar and gain calibration data, in conjunction with mission-long trends of global ocean color data products, to diagnose and correct recently emergent residual drifts in the radiometric response of the instrument.

An anomaly analysis of the time series of global mean normalized water-leaving radiances, the atmospheric correction parameter $\epsilon$, and chlorophyll show significant departures from the mission-long trends beginning in January 2006. The lunar time series trends for the near infrared (NIR) bands (765 nm and $865 \mathrm{~nm}$ ) show significant periodic departures from mission-long trends beginning at the same time. $\epsilon$ is dependent on the ratio of these two bands; trends in this parameter would propagate through the atmospheric correction algorithm to the retrieved water-leaving radiances. An analysis of fit residuals from the lunar time series shows that the focal plane temperature dependencies of the radiometric response of the detectors for these two bands have changed over the $9+$ year mission. The Cal/Val Team has used these residuals to compute a revised set of temperature corrections for data collected starting 1 January 2006. The lunar calibration data and a mission-long ocean color test data set have been reprocessed with the revised temperature corrections. The reprocessed data show that the trends in the NIR bands have been minimized and that the departures of the water-leaving radiances, $\epsilon$, and chlorophyll from the mission-long trends have been greatly reduced.
\end{abstract}

The anomaly analysis of the water-leaving radiances in the $510 \mathrm{~nm}$ band still shows a residual drift of $-2.9 \%$ over the mission. The anomaly analysis of the $\epsilon$ time series shows a residual drift of $+2.8 \%$ over the mission. A corresponding drift is not observed in the lunar calibration time series for the NIR bands. The lunar calibration data are obtained at a different set of instrument gains than are the ocean data. An analysis of the mission-long time series of on-orbit gain calibration data shows that the gain ratios for the NIR bands change $-0.76 \%(765 \mathrm{~nm})$ and $+0.56 \%(865 \mathrm{~nm})$ over the mission, corresponding to a $-1.3 \%$ drift in the band ratio. The lunar calibration time series for the NIR bands have been corrected for this gain drift, and the change in radiometric response over time has been recomputed for each band. The mission-long ocean color test data set has been reprocessed with these revised corrections for the NIR bands. The anomaly analysis of the reprocessed water-leaving radiances at $510 \mathrm{~nm}$ shows the drift to have been essentially eliminated, while the anomaly analysis of epsilon shows a reduced drift of $+2.0 \%$.

These analyses show the sensitivity of ocean color data to small drifts in instrument calibration and demonstrate the use of time series of global mean geophysical parameters to monitor the long-term stability of the instrument calibration on orbit. The two updates to SeaWiFS radiometric calibration have been incorporated into the recent reprocessing of the SeaWiFS mission-long ocean data set.

Keywords: SeaWiFS, ocean color, calibration, measurement trends

Further author information: (Send correspondence to R.E.E.)

R.E.E.: E-mail: Robert.E.Eplee@nasa.gov, Telephone: 3012860953

F.S.P.: E-mail: Frederick.S.Patt@nasa.gov, Telephone: 3012865723

G.M.: E-mail: Gerhard.Meister-1@nasa.gov, Telephone: 3012860758

B.A.F.: E-mail: Bryan.A.Franz@nasa.gov, Telephone: 3012865429

S.W.B.: E-mail: Sean.W.Bailey@nasa.gov, Telephone: 3012863931

C.R.M.: E-mail: Charles.R.McClain@nasa.gov, Telephone: 3012865377 
Table 1. SeaWiFS Bands. The nominal center wavelengths and bandwidths are in nanometers.

\begin{tabular}{|c|c|c|c|c|c|c|c|c|}
\hline Band & $\mathbf{1}$ & $\mathbf{2}$ & $\mathbf{3}$ & $\mathbf{4}$ & $\mathbf{5}$ & $\mathbf{6}$ & $\mathbf{7}$ & $\mathbf{8}$ \\
\hline Wavelength & 412 & 443 & 490 & 510 & 555 & 670 & 765 & 865 \\
\hline Bandwidth & 20 & 20 & 20 & 20 & 20 & 20 & 40 & 40 \\
\hline
\end{tabular}

\section{INTRODUCTION}

One of the goals of climate change research is to discern small secular trends in geophysical processes that may have comparatively large daily, seasonal, or longer-scale periodic signals. This research requires remote sensing data from instruments with long-term radiometric stability, where the radiometric uncertainty in the data is less than the magnitude of the possible climate change signal. For ocean color data, the radiometric requirements are 5\% absolute and 1\% relative accuracies on the water-leaving radiances and $35 \%$ accuracy for chlorophyll a concentrations in open-ocean regions. ${ }^{1}$ Because open-ocean reflectances are low, approximately $90 \%$ of the top-of-the-atmosphere (TOA) signal observed by ocean color satellite instruments is due to scattering of sunlight by gases and aerosols within the atmosphere. The ocean color atmospheric correction algorithm must remove this signal to yield the water-leaving radiances. Uncertainties in the sensor calibration and in the atmospheric correction algorithm require a vicarious calibration of the sensor/atmospheric correction algorithm system that is independent of time to achieve these accuracy requirements. ${ }^{2}$ Because of the amplification of any errors in the sensor calibration by the atmospheric correction process, the $1 \%$ relative accuracy requirement on water-leaving radiances translates into a $0.1 \%$ long-term radiometric stability requirement for TOA radiances.

The Sea-viewing Wide Field-of-view Sensor (SeaWiFS) has been providing daily global imagery of the world's oceans since September 1997. The goal of the NASA Ocean Biology Processing Group's (OBPG) Calibration and Validation (Cal/Val) Team is to produce a long-term ocean color data set that meets the high radiometric accuracy and long-term stability required for climate change research. SeaWiFS is an eight-band visible and near-infrared scanning radiometer designed to have high radiometric sensitivity over oceans without saturating over bright clouds. The bands are provided in Table 1 .

To meet the radiometric accuracy requirements, the Cal/Val team has implemented an on-orbit calibration strategy that uses monthly lunar calibrations to monitor changes the radiometric response of the instrument over its mission lifetime and uses daily solar calibrations to look for short-period, step-function changes in the instrument response. ${ }^{3-5}$ The Cal/Val Team has also used data from the NASA/NOAA Marine Optical Buoy (MOBY) to vicariously calibrate the integrated instrument and atmospheric correction algorithm system. ${ }^{6,7}$ SeaWiFS obtains Earth measurements with detectors whose standard gains were optimized prior to launch for the expected typical top-of-the-atmosphere radiances over the ocean in the visible (400-700 nm) and nearinfrared (700-900 nm) bands. Lunar radiances obtained at the standard gains would saturate the ocean detectors. Accordingly, the Cal/Val Team's on-orbit calibration strategy requires that changes in the radiometric response of the instrument, derived from lunar data obtained at the lunar commanded gains, be applied to ocean data obtained at the standard gains. To keep the lunar and solar measurements from saturating the detectors, the instrument electronics incorporate four selectable gain stages. Gain 1 is the standard gain for TOA radiances over the ocean. Gain 2 is the secondary gain for ocean observations (set at $2 \mathrm{X}$ the standard gain) designed to maintain the ocean color time series in the event of severe degradation of the radiometric response of a given band, and has yet to be used operationally. Gain 3 is a commanded gain set to give $3 / 4$ full scale output from the instrument for lunar calibrations, while Gain 4 is a commanded gain set to give $3 / 4$ full scale output for solar measurements. After the initial lunar and solar gains were defined, the optimum gains for those measurements were recomputed. The actual commanded gains used on-orbit for ocean, lunar, and solar measurements are shown in Table 2.

The ultimate validation of this on-orbit calibration strategy for ocean color data is the stability of the ocean color products themselves. Because of the sensitivity of the water-leaving radiance and chlorophyll retrievals to small changes in the instrument calibration, ${ }^{4}$ the Cal/Val Team has used a mission-long time series of the 8-day composite global mean ocean color data products to validate the long-term stability of the on-orbit calibration of the instrument. ${ }^{8}$ SeaWiFS, having nearly completed the tenth year of its mission, provides the Earth remote 
Table 2. SeaWiFS Gains. Gain 1 is the standard gain for ocean observations. Gain 2 is the secondary gain (2x) for ocean observations. Gain 3 and Gain 4 are the commanded gains designed to give 3/4 full scale output for lunar and solar observations.

\begin{tabular}{|c|c|c|c|}
\hline Target & Band 1 & Band 2 & Bands 3-8 \\
\hline ocean & Gain 1 & Gain 1 & Gain 1 \\
lunar & Gain 4 & Gain 3 & Gain 3 \\
solar & Gain 3 & Gain 1 & Gain 3 \\
$\mathbf{2 X}$ & Gain 2 & Gain 2 & Gain 2 \\
\hline
\end{tabular}

sensing community with the opportunity to understand how sensors perform on orbit over such long mission periods. The SeaWiFS experience highlights the importance of mission-long on-orbit calibration and validation data sets to the generation and maintenance of a long-term, climate quality ocean color data set.

\section{EMERGENT DRIFTS IN INSTRUMENT RESPONSE}

The SeaWiFS atmospheric correction algorithm uses the ratio of aerosol radiances in the near-infrared (NIR) bands, band $7(765 \mathrm{~nm})$ and band $8(865 \mathrm{~nm})$, to propagate the observed aerosol radiances from the NIR bands to the visible bands. ${ }^{9}$ This ratio is characterized by the parameter $\epsilon$ :

$$
\epsilon(\lambda, 865)=\frac{L_{a s}(\lambda) F_{0}(865)}{L_{a s}(865) F_{0}(\lambda)}
$$

Here, $L_{a s}$ is the single-scattering aerosol radiance and $F_{0}$ is the solar constant. In the atmospheric correction algorithm, $\epsilon$ is evaluated for band 7 and then used to extrapolate the aerosol radiance at band 8 to the visible bands (bands 1-6). Any drifts in $\epsilon$ over the mission would propagate through the atmospheric correction algorithm into the water-leaving radiance and chlorophyll retrievals.

This analysis examines long-term trends in the level-3 ocean color products (water-leaving radiances for bands 1-6, chlorophyll, and $\epsilon$ ) and the consistency of those trends from year to year. It provides a standard mechanism for evaluating derived product and sensor stability, and it quantifies the relative impact of calibration and algorithm changes on global spatial scales and life-of-mission time scales. The approach begins with the level-3 products. These products are global binned, multi-day averages at 9-km resolution, with bins distributed in an equal-area, sinusoidal projection. The typical composite period is 8-days, but for quick turn-around test processing the Cal/Val Team uses a temporal subset of the mission lifespan consisting of 4-day composites generated from the start of each consecutive 32-day period. The temporal subset is generated at 9-km resolution, and it can be processed within one day. The 4-day compositing period generally provides sufficient opportunity to observe most of the daylit side of the earth, including coverage in orbit and glint gaps. From these global, multi-day composites, a subset of the filled bins is selected and the ocean products are averaged and trended with time. For the analysis reported here, the Cal/Val Team uses a global deep water data subset, which consists of all bins where water depth is greater than 1000 meters. Annual climatologies are computed for the ocean products for both the 8-day and 4-day time series, using the $9+$ year-long mission data set. Anomaly plots are then generated for each product, where the anomaly is defined as the long-term trend with the annual climatology subtracted. In this analysis, 114 composites are used which span the time range of November 1997 through May 2007.

The initial set of anomaly plots for the deepwater subset of the level-3 ocean color products is shown in Fig. 1. These plots show normalized water-leaving radiances $\left(L_{W N}\right)$ for bands $1-6(412 \mathrm{~nm}, 443 \mathrm{~nm}, 490 \mathrm{~nm}$, $510 \mathrm{~nm}, 555 \mathrm{~nm}$ and $670 \mathrm{~nm}), \epsilon$, and chlorophyll, along with linear trends fit to each time series. Examination of these plots show significant departures from the mission-long trends for $L_{W N}(490), L_{W N}(510), L_{W N}(555)$, $L_{W N}(670)$, and $\epsilon$, with smaller departures for $L_{W N}(412)$ and $L_{W N}(443)$, starting around 1 January 2006. The $\mathrm{Cal} / \mathrm{Val}$ Team proceeded to investigate any correlation between these departures from mission-long trends and changes in the radiometric calibration of the instrument. 

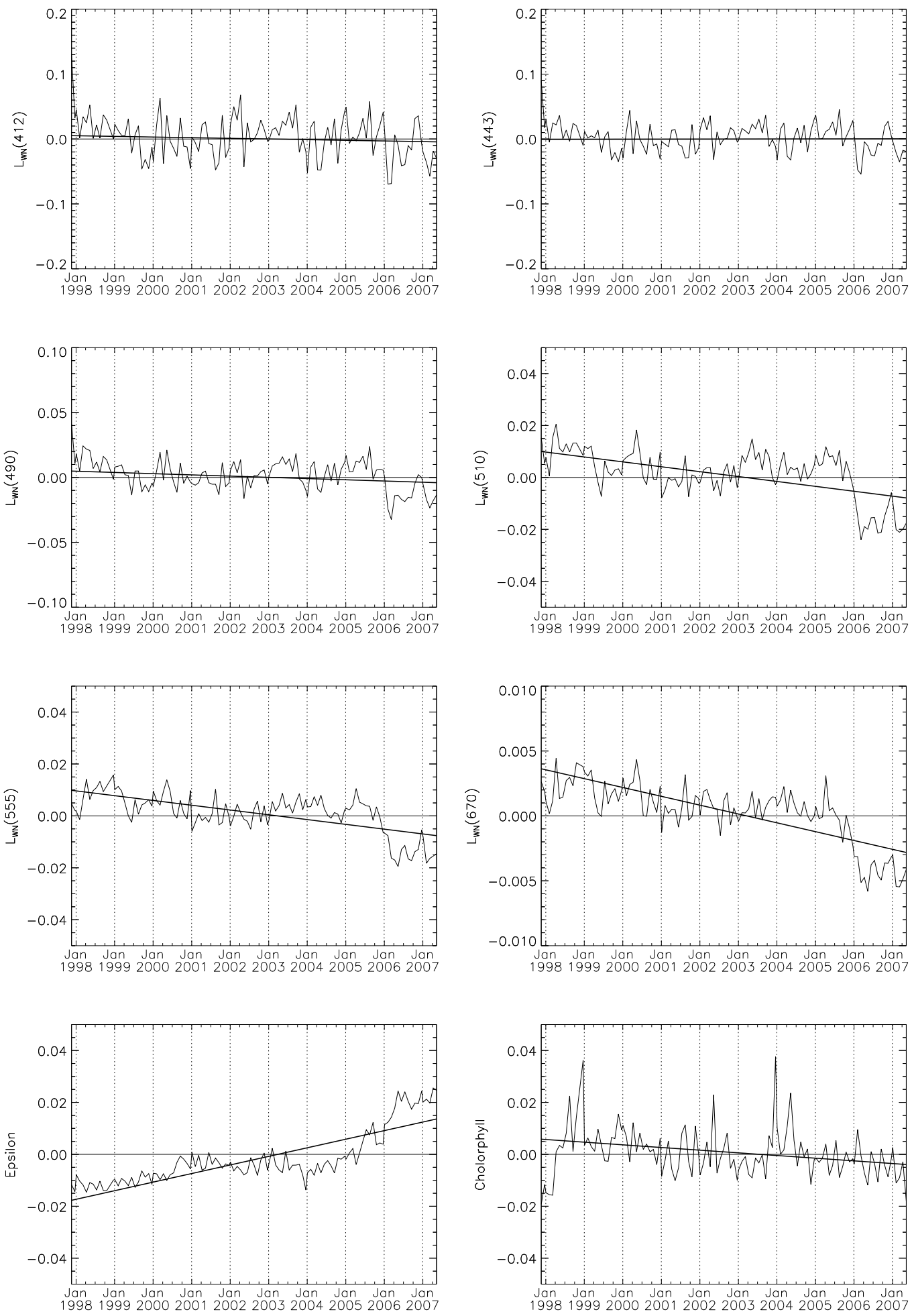

Figure 1. Level-3 Time Series Anomaly Plots. These plots show the mission-long trends with the annual climatologies subtracted. The trend lines are linear fits to the anomaly data. 


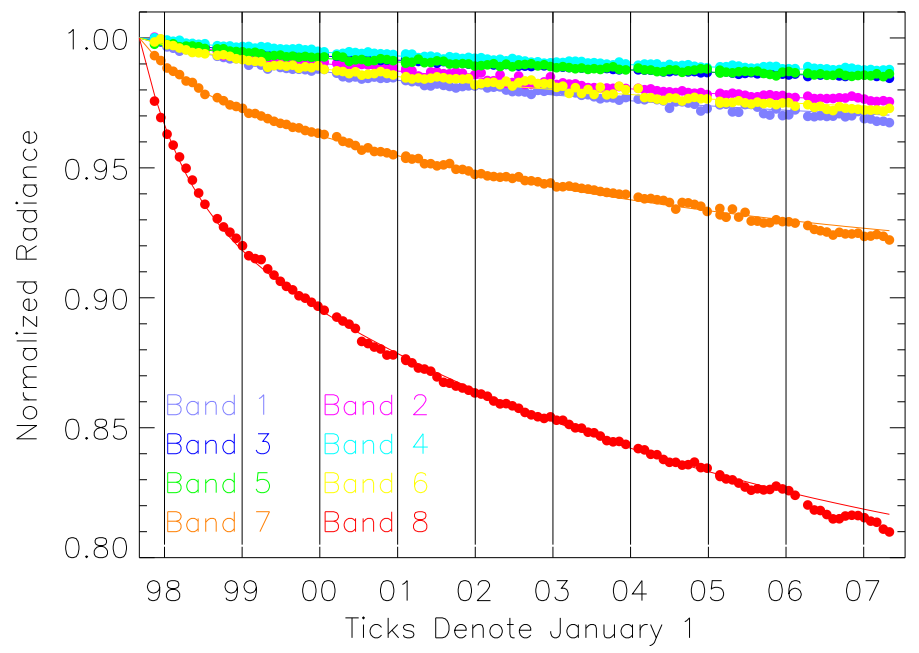

Figure 2. Lunar Calibration Time Series.

\section{LUNAR CALIBRATION DATA ANALYSIS}

To monitor the radiometric response of the instrument, the Cal/Val Team maintains an ongoing analysis of the mission-long SeaWiFS lunar calibration time series, currently encompassing 114 monthly lunar observations spanning some 3400 days from November 1997 through May 2007. The individual lunar observations have been normalized to a common viewing geometry for this analysis. Corrections computed from the time and geometry of the observations include Sun-Moon and instrument-Moon distances, oversampling of the lunar image (computed from the measured size of the lunar images in the along-track direction), and variations in the phase and libration angles of the Moon during the observations. ${ }^{5}$ The Cal/Val Team has fit the corrected lunar calibration time series by two simultaneous decaying exponential functions of time, with time constants of 200 and 2500 days, as shown in Fig. 2. The inverses of these fits constitute the radiometric corrections that are incorporated into the SeaWiFS calibration tables. The lunar time series for bands 7 and 8 show significant departures from the mission-long trends (or exponential fits) beginning in January 2006. These departures are the likely cause of the departures observed in the anomaly analysis of the ocean data products. Some change in the instrument or in the spacecraft environment has given rise to these drifts in instrument response. One likely cause of this change is the drift in the node of the satellite orbit.

Over the mission lifetime, the satellite orbit has decayed from an initial altitude of $705 \mathrm{~km}$ (with a node crossing time of 12:00 noon) to a current altitude of $690 \mathrm{~km}$ (with a node crossing time of 12:55 pm). The node drift is shown in Fig. 3. The lunar time series departures for bands 7 and 8 begin when the node drift becomes larger than $9^{\circ}$. As the node drifts away from noon, the thermal environment of the spacecraft changes due to the changing solar insolation. Consequently, the Cal/Val team has investigated the possibility that changes in the temperature dependence of the radiometric response of the detectors are the cause of the drifts from the mission-long trends for these two bands.

The dependencies of the radiometric response of the detectors on the focal plane temperatures were originally determined during the prelaunch characterization of SeaWiFS. ${ }^{10}$ The focal plane temperature correction for the level-1b calibration equation has the form:

$$
f(\lambda, T)=1.0+K(\lambda)\left(T-T_{\text {ref }}\right)
$$

where:

$K \equiv$ focal plane temperature correction coefficient

$T \equiv$ focal plane temperature $(\mathrm{C})$

$T_{\text {ref }} \equiv$ reference temperature $=20^{\circ} \mathrm{C}$

$\lambda \equiv$ SeaWiFS band 


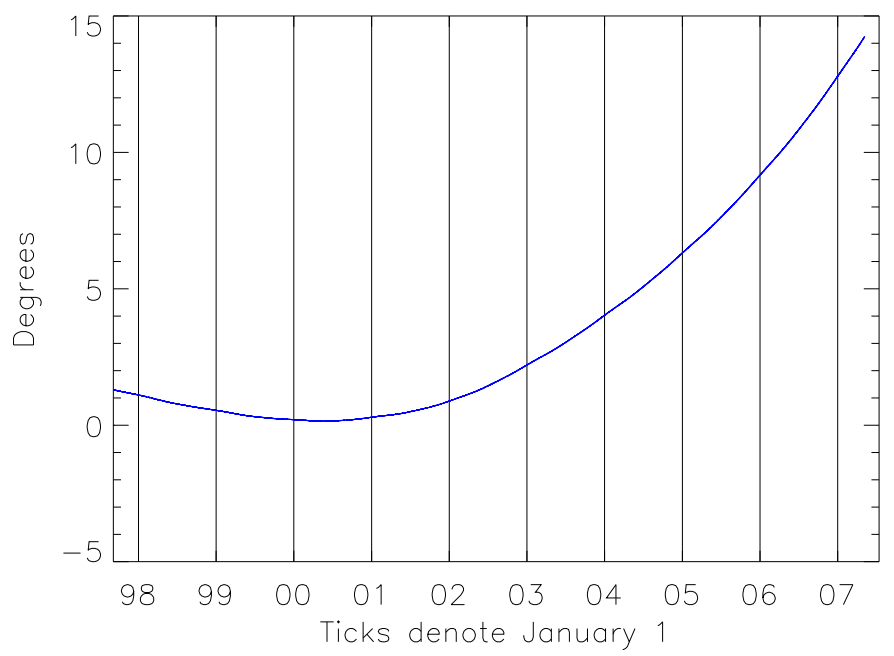

Figure 3. Satellite Orbit Node Drift. The drift is shown as a change in the node from local noon.

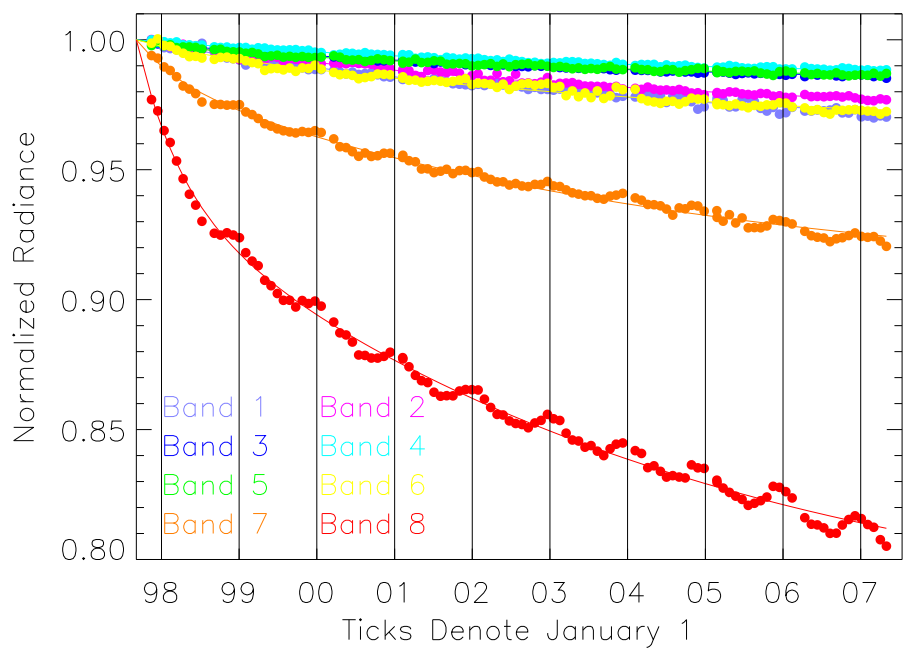

Figure 4. Lunar Calibration Time Series without Focal Plane Temperature Corrections.

After launch, periodic residuals were observed in the lunar calibration time series that correlated with focal plane temperatures. The Cal/Val Team used the lunar time series of 28 observations to compute a revised set of focal plane temperature corrections prior to the fourth global reprocessing of the SeaWiFS mission data set. ${ }^{4,11}$ To investigated the possibility that changes in the temperature dependence of the radiometric response of the detectors are the cause of the emergent drifts from the mission-long trends for bands 7 and 8 , the Cal/Val Team has taken the same approach as before and processed the lunar calibration time series with the focal plane temperature corrections turned off. These time series, along with the simultaneous exponential fits to the time series, are shown in Fig. 4. The time series for band 8 shows how the changing thermal environment of the spacecraft impacts the radiometric response of the instrument.

The changing thermal environment of the instrument is shown in Fig. 5, where the focal plane temperatures for bands 7 and 8 at the time of the lunar calibrations are plotted as a function of time. As the node drifts, the maxima and minima in the annual lunar calibration temperature cycle decrease. The time series of residuals of the exponential fits for band 8, shown in Fig. 6, are correlated with the focal plane temperatures. The time series of the band 8 fit residuals show a change in the mission-long behavior around 1 January 2006 - there is a jump in the annual cycle of the residuals at this time. The residuals of the fits, when plotted against the focal 


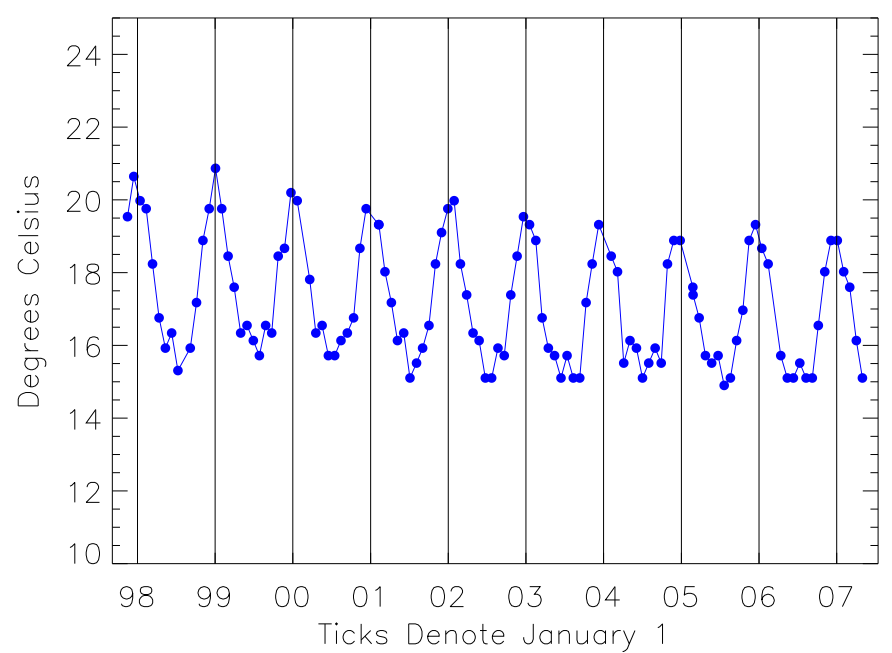

Figure 5. SeaWiFS Thermal Environment at Lunar Calibrations. The temperatures for the band $7 / 8$ focal plane are shown.

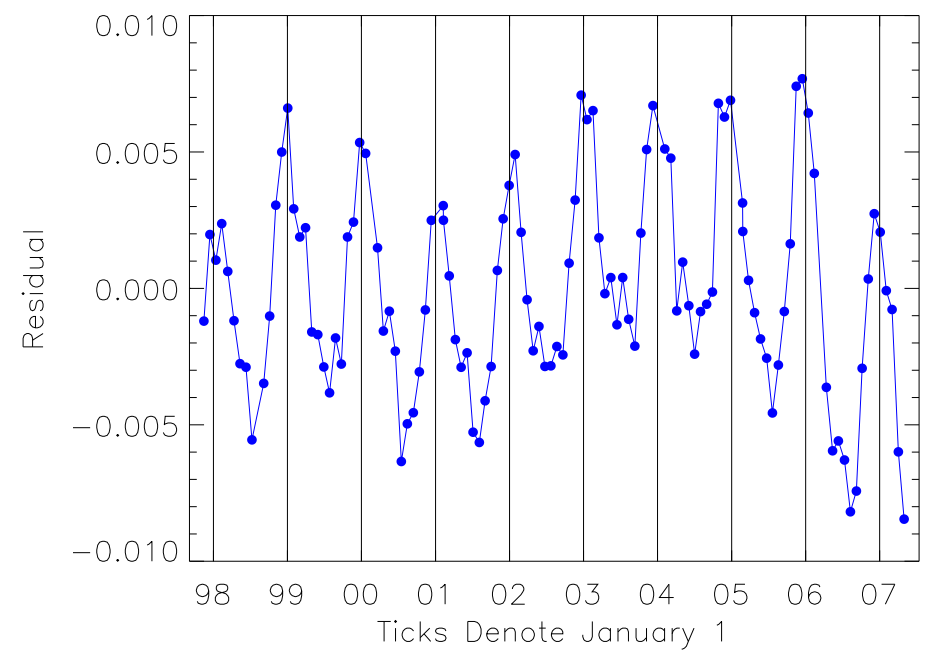

Figure 6. Band 8 Lunar Calibration Time Series Fit Residuals. The residuals are correlated with the focal plane temperatures.

plane temperatures, allow the focal plane temperature dependence of the detector response to be evaluated, as shown for band 8 in Fig. 7. The mission-long trend is shown in blue, while the trend since 1 January 2006 is shown in red. The Cal/Val Team has used the fits to the residuals to compute a revised set of temperature corrections for SeaWiFS. The mission long trend provides a set of corrections from the launch through 1 January 2006, while the emergent trend provides a set of corrections from 1 January 2006 onwards. Table 3 shows the prelaunch temperature corrections,${ }^{10}$ the revised set of corrections computed in $2002,{ }^{11}$ and the current revised set of corrections.

The lunar time series, processed with the revised focal plane temperature corrections, are shown in Fig. 8. The departures of the times series for bands 7 and 8 from the mission-long trends have been removed, indicating that the long-term stability of the instrument calibration has been restored. 


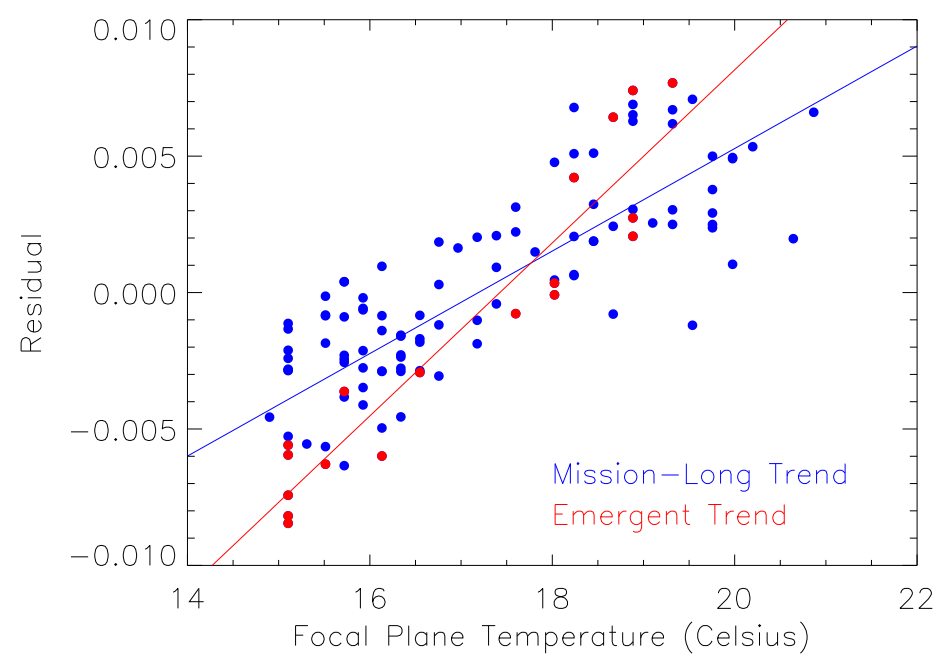

Figure 7. Band 8 Lunar Calibration Time Series Fit Residuals. Both the mission-long residual trend and the emergent residual trend are shown by linear fits to the residuals.

Table 3. Focal plane temperature corrections for SeaWiFS. The first on-orbit corrections were computed using 28 lunar observations. The revised on-orbit corrections were computed using 114 lunar observations. The units are $\left({ }^{\circ} C\right)^{-1}$.

\begin{tabular}{|c|c|c|c|c|c|}
\hline Band & Wavelength & Prelaunch & First On-Orbit & $\begin{array}{c}\text { Revised On-Orbit } \\
\text { Data before 1 Jan 06 }\end{array}$ & $\begin{array}{c}\text { Revised On-Orbit } \\
\text { Data since 1 Jan 06 }\end{array}$ \\
\hline $\mathbf{1}$ & 412 & 0.000901 & 0.0007664 & 0.00066634978 & 0.00052589372 \\
$\mathbf{2}$ & 443 & 0.000585 & 0.0005540 & 0.00048314972 & 0.00048787098 \\
$\mathbf{3}$ & 490 & 0.000420 & 0.0003392 & 0.00030006705 & 0.00011433817 \\
$\mathbf{4}$ & 510 & 0.000390 & 0.0003057 & 0.00030346485 & 0.00016877585 \\
$\mathbf{5}$ & 555 & 0.000391 & 0.0003045 & 0.00034757576 & 0.00018901174 \\
$\mathbf{6}$ & 670 & 0.000151 & -0.00003443 & -0.00066507053 & -0.00023358828 \\
$\mathbf{7}$ & 765 & 0.000106 & -0.0004495 & -0.00037812295 & -0.00094717220 \\
$\mathbf{8}$ & 865 & 0.000078 & -0.001485 & -0.0015401345 & -0.0029935800 \\
\hline
\end{tabular}




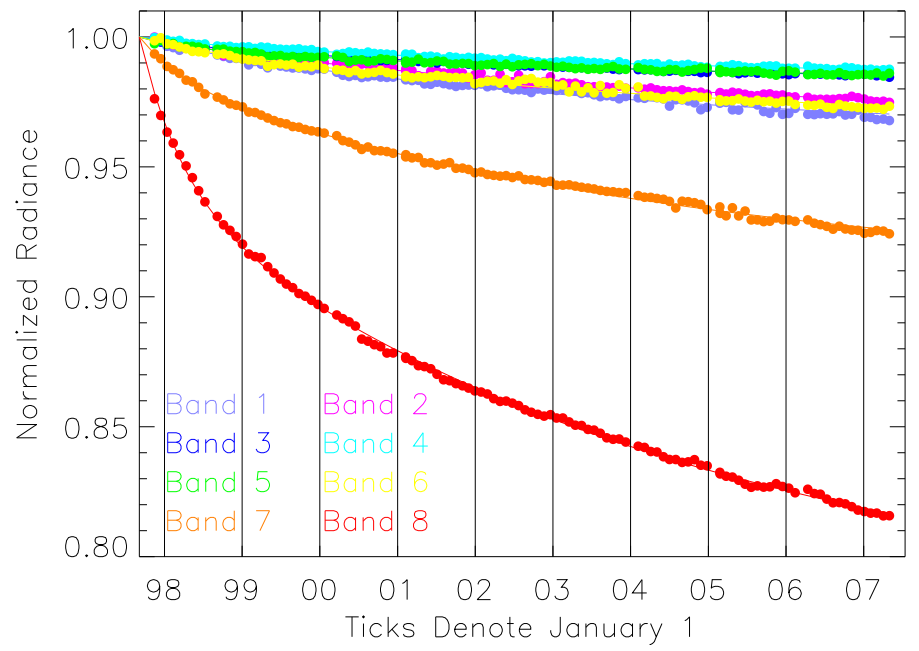

Figure 8. Lunar Calibration Time Series with revised Focal Plane Temperature Corrections.

\section{OCEAN DATA ANOMALY ANALYSIS, REVISITED}

The mission-long ocean color test data set has been reprocessed with the revised temperature corrections for the NIR bands. The revised anomaly plots are shown in Fig. 9. These plots again show normalized water-leaving radiances $\left(L_{W N}\right)$ for bands 1-6 $(412 \mathrm{~nm}, 443 \mathrm{~nm}, 490 \mathrm{~nm}, 510 \mathrm{~nm}, 555 \mathrm{~nm}$ and $670 \mathrm{~nm}), \epsilon$, and chlorophyll, along with linear trends fit to each time series. Examination of these revised plots shows that it is often difficult to distinguish between secular trends in the data, interannual effects (e.g., the El Nino Southern Oscillation), and possible residual drifts in the instrument calibration. The anomaly plot for $L_{W N}(510)$ should not show any trends even in the presence of secular trends in chlorophyll or aerosols. However, this plot does show an unexplained decrease of $0.020 \mathrm{~mW} \mathrm{~cm}^{-2} \mathrm{sr}^{-1} \mu \mathrm{m}^{-1}$ in this band over the mission (a $2.9 \%$ change), with an accompanying increase for $\epsilon$ of 0.030 over the mission (a $2.8 \%$ change). This trend in $\epsilon$ has been ascribed by Wang et al. ${ }^{12}$ to uncorrected drifts in the calibration of bands 7 and 8 . The Cal/Val Team proceeded to investigate any correlation between the trends in $L_{W N}(510)$ and $\epsilon$ and any further drifts in the radiometric calibration of the instrument.

\section{GAIN CALIBRATION DATA ANALYSIS}

Lunar radiances obtained at the standard gains would saturate the ocean detectors. Accordingly, the Cal/Val Team's on-orbit calibration strategy requires that changes in the radiometric response of the instrument, derived from lunar data obtained at the lunar commanded gains, be applied to ocean data obtained at the standard gains. Consequently, the Cal/Val team must monitor the temporal stability of the gain ratios for each band. The gain ratios are computed from the on-orbit gain calibrations, where a constant voltage signal (calibration pulse) in injected into the post-detector electronics while the instrument steps through the commanded gains for each of the detectors. The gain calibrations are performed daily immediately following the solar calibrations, providing a time series of the gain ratios.

The Cal/Val Team has undertaken an analysis of the mission-long time series of 3400 daily gain calibrations, spanning some 3500 days from the start of on-orbit operations in September 1997 through May 2007. For each on-orbit gain calibration, calibration pulse data is collected for 6 scan lines (1 second of data collection) while the instrument cycles through the gain sequence $(1,2,1,3,1,4,1)$. The gain ratios (GR1, GR2, GR3, GR4) for a given band are defined relative to Gain 1 as follows:

$$
G R X(\lambda)=\frac{C P(\operatorname{Gain} X, \lambda)}{C P(\operatorname{Gain} 1, \lambda)} .
$$

Here X designates the commanded gain (Gain 1, Gain 2, Gain 3, or Gain 4), $\lambda$ designates the band, and $C P(\operatorname{Gain} X, \lambda)$ is the output counts from the band for a commanded gain, with the calibration pulse as input. 

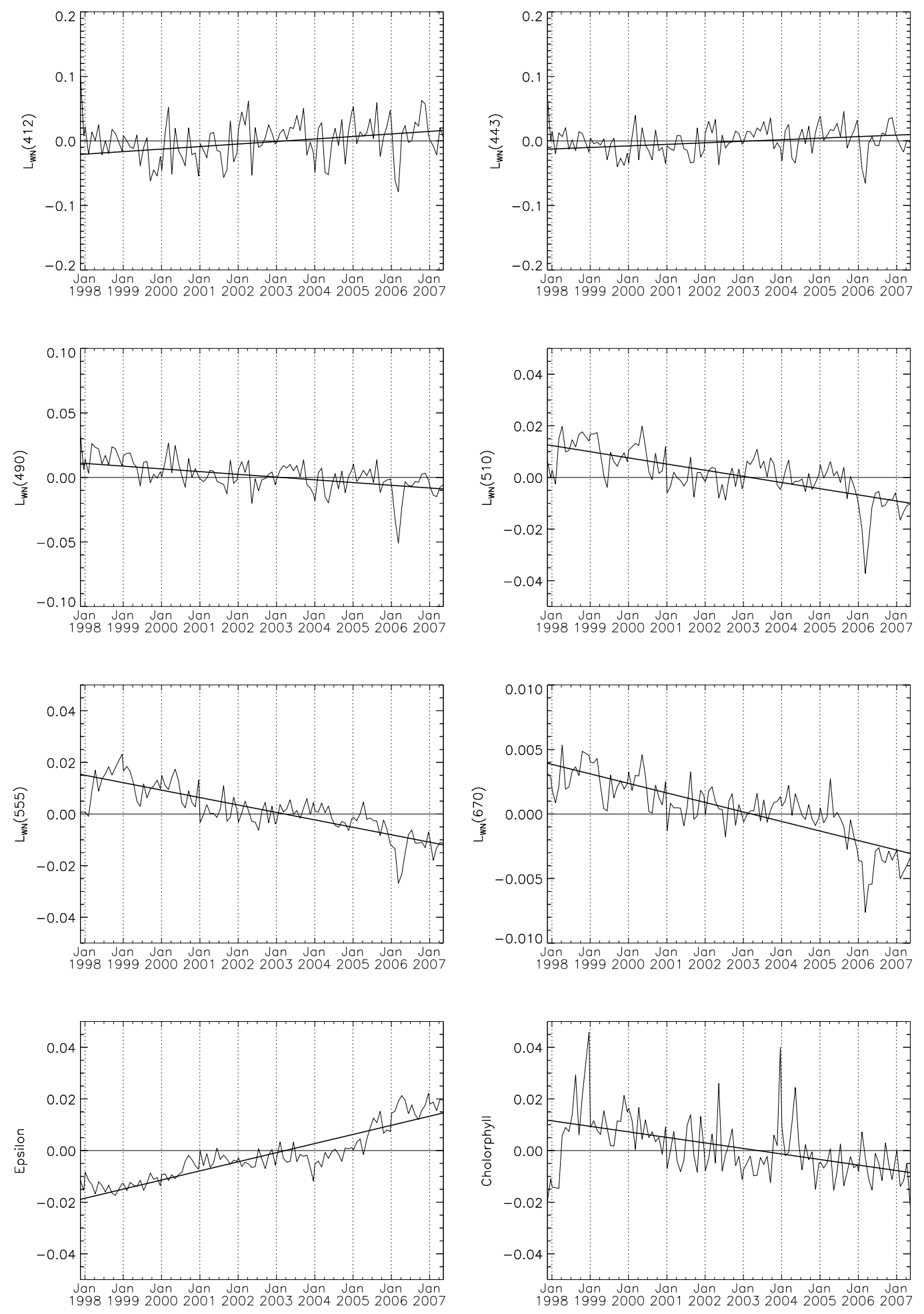

Figure 9. Level-3 Time Series Anomaly Plots. These data have been reprocessed with the revised focal plane temperature corrections. 
Table 4. Vicarious gains for SeaWiFS. $\Delta$ are the change in the gains due to the GR3 drift corrections.

\begin{tabular}{|c|c|c|c|c|}
\hline Band & Wavelength & $\begin{array}{c}\text { Gain before } \\
\text { Correction }\end{array}$ & $\begin{array}{c}\text { Gain after } \\
\text { Correction }\end{array}$ & $\Delta(\%)$ \\
\hline $\mathbf{1}$ & 412 & 1.0367 & 1.0368 & 0.0096 \\
$\mathbf{2}$ & 443 & 1.0128 & 1.0129 & 0.0099 \\
$\mathbf{3}$ & 490 & 0.9913 & 0.9914 & 0.010 \\
$\mathbf{4}$ & 510 & 0.9975 & 0.9978 & 0.030 \\
$\mathbf{5}$ & 555 & 0.9987 & 0.9989 & 0.020 \\
$\mathbf{6}$ & 670 & 0.9724 & 0.9728 & 0.041 \\
$\mathbf{7}$ & 765 & 0.9691 & 0.9717 & 0.27 \\
$\mathbf{8}$ & 865 & 1.00 & 1.00 & \\
\hline
\end{tabular}

Gain ratios are computed for individual detectors within a band in a similar manner. This analysis examines the gain ratio time series for possible trends. The reference time for the time series is the time of the first SeaWiFS on-orbit image, 16 hours 30 minutes UT on September 4, 1997.

The time series of gain ratios for each band at the lunar calibration gains are shown in Fig. 10. For bands 1-6, the gain ratios change less than $0.1 \%$ over the mission. Such small changes in the gain ratios would have a negligible impact on the Earth observations. For band 7 the gain ratio decreases by $0.76 \%$ over the mission and for band 8 the gain ratio increases by $0.56 \%$ over the mission. The impact of these drifts on the ocean products comes through the NIR band ratio, which is plotted in Fig. 11. The drift in the band ratio over the mission is $-1.3 \%$, which is comparable to the drift in $\left.L_{W N} 510\right)$ and $\epsilon$. In order to correct the calibration of the instrument for gain ratio drift, the Cal/Val Team has computed a series of piecewise linear fits to GR3 for bands 7 and 8. These fits have been used to correct the lunar calibration time series for the gain drift. The Cal/Val Team then recomputed the change in the radiometric response of the instrument over time for these two bands and generated a revised SeaWiFS calibration table.

\section{FINAL OCEAN DATA ANOMALY ANALYSIS}

As a first assessment of the GR3 drift correction on the ocean products, the Cal/Val Team examined changes in the vicarious calibration of SeaWiFS. The vicarious calibration adjusts the integrated instrument and atmospheric correction algorithm system to retrieve normalized water-leaving radiances that are in agreement with ground truth measurements using data from the Marine Optical Buoy (MOBY) and observations of clear-water sites in the South Pacific and southern Indian Ocean. ${ }^{6,7}$ The calibration produces a set of multiplicative gains for the TOA radiances in each band that are independent of time and location. For the NIR bands, the Cal/Val Team assumes that the vicarious gain of the $865 \mathrm{~nm}$ band is unity and adjusts the gain of the $765 \mathrm{~nm}$ band so that the atmospheric correction algorithm retrieves the expected aerosol models for selected open-ocean scenes. The Team then adjusts the vicarious gains of the visible bands to match the $L_{W N}$ measured by MOBY. The comparison of the vicarious gains for SeaWiFS before and after the GR3 drift correction are shown in Table 4. Changing the gain of band 8 causes a change in the total aerosol radiance retrieved by the atmospheric correction algorithm, since the vicarious gain for band 8 is unity. Changing the gains of bands 7 and 8 causes a change of almost $0.3 \%$ in the vicarious calibration of band 7 . For the visible bands, changes in the total aerosol radiance would have a larger effect in the green bands than the blue bands, since the aerosol radiance is a larger component of the TOA radiance for the green bands. Consequently, changing the gains of the NIR bands together propagates into a steadily decreasing effect with shorter wavelemgth in the vicarious calibration of the visible bands.

The mission-long ocean color test data set has been reprocessed with the revised temporal corrections for the NIR bands. The revised anomaly plots are shown in Fig. 12. The drift in $L_{W N}(510)$ has essentially been eliminated and the drift in $\epsilon$ has been reduced to 0.023 (2.3\% over the mission). The changes in $L_{W N}$ for the other bands and in the chlorophyll are of the expected magnitude arising from the change in $\epsilon$. The source of 

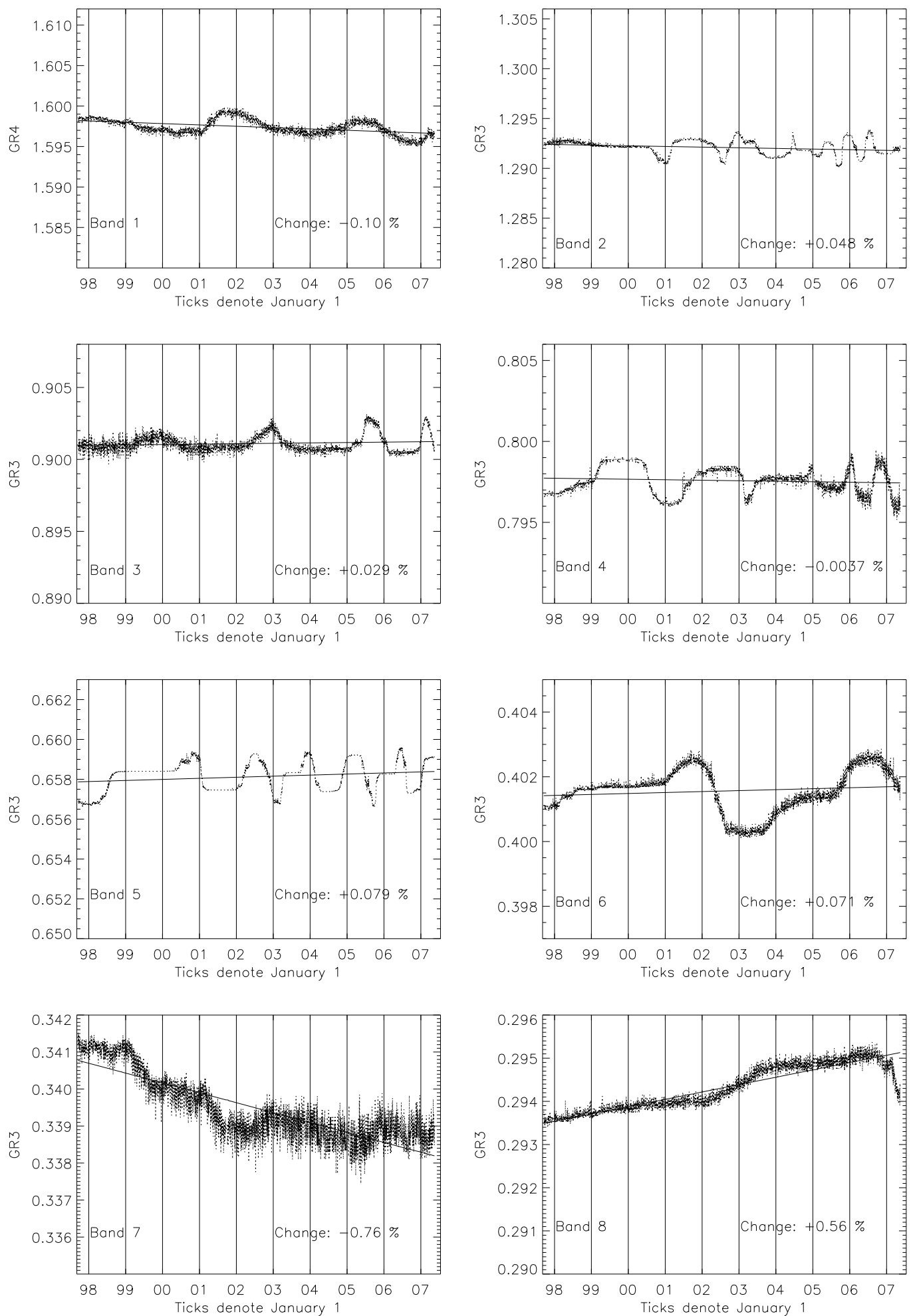

Figure 10. Lunar Gain Ratio Time Series Plots. 


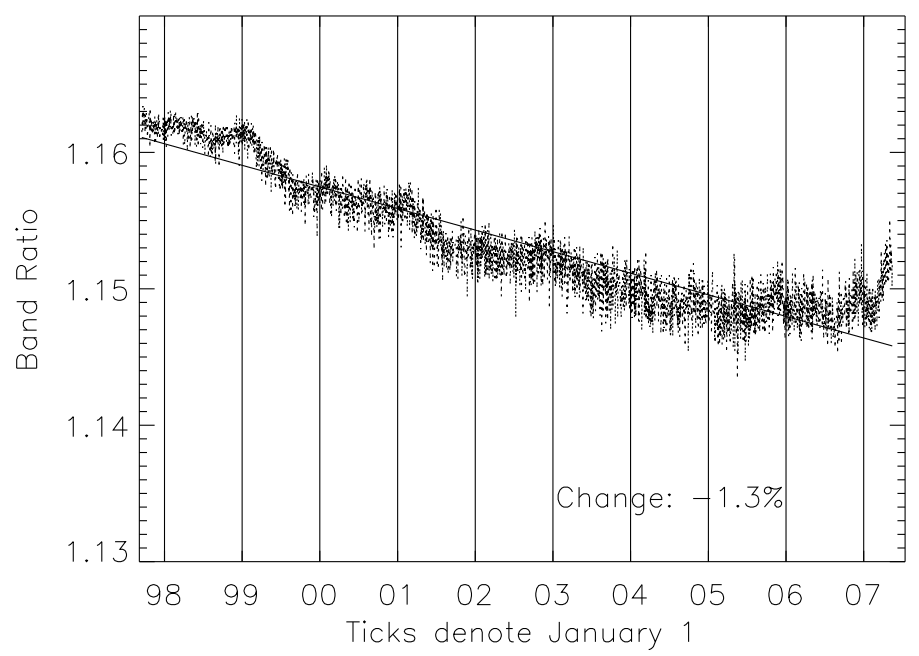

Figure 11. SeaWiFS Band 7 / Band 8 Ratio Time Series.

the residual trend in $\epsilon$ may be due to changing aerosol concentration in the atmosphere over the mission, as is suggested by Fukushima et al. ${ }^{13}$ for East Asia, though the global extent of such changes have not been verified. ${ }^{12}$ This analysis shows the sensitivity of ocean color data to small drifts in the instrument calibration over time and demonstrates the use of time series of global mean products to monitor changes in the instrument response. The update to SeaWiFS calibration to correct for the G3 drift in the NIR bands will be incorporated into the recent reprocessing of the SeaWiFS mission-long ocean data set. By making the G3 drift correction for the NIR bands, the Cal/Val Team will maintain the validity of applying changes in the radiometric response of SeaWiFS derived from lunar data obtained at the lunar commanded gains to ocean data obtained at the standard gains.

\section{DISCUSSION}

The primary purpose of a rigorous on-orbit calibration program for any remote sensing satellite instrument is to assure the long-term radiometric stability of that instrument Since SeaWiFS has almost completed the tenth year of its mission, analysis of its on-orbit calibration data provides a unique opportunity to study long-term trends in the radiometric performance of scanning filter radiometers. This study demonstrates the importance of a mission-long calibration/validation program to the generation and maintenance of a long-term climate quality ocean color data set. More specifically, this work shows the sensitivity of ocean color data to small drifts in instrument calibration and demonstrates the use of time series of global mean geophysical parameters to validate the long-term stability of the instrument calibration on orbit This work demonstrates that a sufficiently-long, well-characterized lunar calibration data set can provide a tool to evaluate other aspects of the on-orbit behavior of the instrument, as well. For SeaWiFS, the lunar calibration time series has allowed the investigation of focal plane temperature effects on the radiometric response of the instrument. This study also shows that a robust on-orbit calibration strategy for any instrument should monitor the key performance aspects of the primary calibration method. For SeaWiFS, the necessity of obtaining lunar measurements at different instrument gains from the Earth observations required the implementation of an on-orbit gain calibration. The OBPG Cal/Val Team, through its use of mission-long time series of on-orbit gain ratios, ensures that changes in the radiometric response of SeaWiFS derived from lunar data obtained at one set of commanded gains can be applied to ocean data obtained at a different set of gains. While these specific calibration strategies are unique to SeaWiFS, the SeaWiFS experience should influence the development of future ocean color missions.

The SeaWiFS gain calibration experience shows that future missions would benefit by expanding the dynamic range of new instruments to cover both typical radiances for the Earth observations and radiances from the calibration sources (the Moon or solar diffusers). MODIS uses this approach with the limitation that ocean color bands 13-16 (667 nm, $678 \mathrm{~nm}, 748 \mathrm{~nm}$, and $869 \mathrm{~nm})$ saturate on the Moon. An alternate approach for 

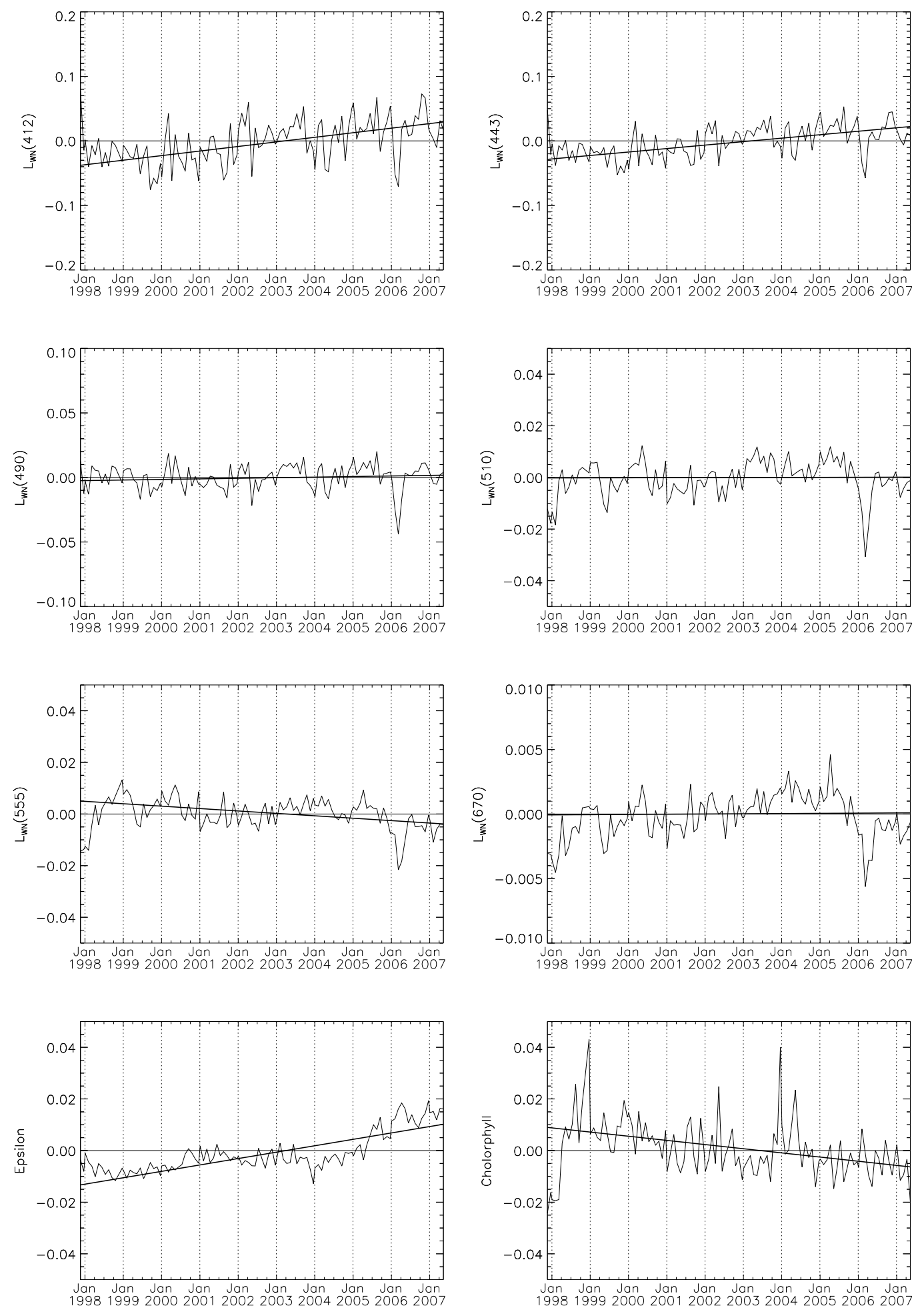

Figure 12. Level-3 Time Series Anomaly Plots. These data have been reprocessed with the revised focal plane temperature corrections and with the gain 3 drift correction. 
future missions would be to maintain separate on-orbit calibrations for each instrument gain. Such a calibration strategy is currently under development for the Visible and Infrared Radiometer Suite (VIIRS) on the National Polar-orbiting Operational Environmental Satellite System (NPOESS) and NASA NPOESS Preparatory Project.

This experience shows the necessity of maintaining mission-long time series of global mean data products for Earth-observing sensors to evaluate the both the derived product and sensor calibration stability. These time series are sensitive monitors to small changes in the calibration of the instruments on orbit. The OBPG maintains these time series for SeaWiFS and MODIS. Such an approach will be required by the NPOESS Preparatory Project to assure that climate quality data can be obtained from VIIRS.

\section{REFERENCES}

1. C.R. McClain, W.E. Esaias, W. Barnes, B. Guenther, D. Endres, S.B. Hooker, G. Mitchell, and R. Barnes, SeaWiFS Calibration and Validation Plan, NASA Tech. Memo. 104566 3, S.B. Hooker and E.R. Firestone, eds., (NASA Goddard Space Flight Center, Greenbelt, Maryland), (1992).

2. R.H. Evans and H.R. Gordon, "Coastal Zone Color Scanner 'system calibration': A retrospective examination," J. Geophys. Res. 99, 7293-7303, (1994).

3. R.A. Barnes, R.E. Eplee, Jr., F.S. Patt, and C.R. McClain, "Changes in the radiometric stability of SeaWiFS determined from lunar and solar-based measurements," Appl. Opt. 38, 4649-4664, (1999).

4. R.A. Barnes, R.E. Eplee, Jr., G.M. Schmidt, F.S. Patt, and C.R. McClain, "Calibration of SeaWiFS. I. Direct techniques," Appl. Opt. 40, 6682-6700, 2001.

5. R.E. Eplee, Jr., R.A. Barnes, F.S. Patt, G. Meister, and C.R. McClain, "SeaWiFS lunar calibration methodology after six years on orbit," in Earth Observing Systems IX, W.L. Barnes and J.J. Butler, eds., Proc. SPIE 5542, 1-13, 2004.

6. R.E. Eplee, Jr., W.D. Robinson, S.W. Bailey, D.K. Clark, P.J. Werdell, M. Wang, R.A. Barnes, and C.R. McClain, "Calibration of SeaWiFS. II. Vicarious techniques," Appl. Opt. 40, 6701-6718, (2001).

7. B.A. Franz, S.W. Bailey, P.J. Werdell, and C.R. McClain, "Sensor-independent approach to the vicarious calibration of satellite ocean color radiometry," Appl. Opt. 46 (24), (2007).

8. B.A. Franz, P.J. Werdell, G. Meister, S.W. Bailey, R.E. Eplee, Jr., G.C. Feldman, E. Kwaitkowska, C.R. McClain, F.S. Patt, and D. Thomas, "The continuity of ocean color measurements from SeaWiFS to MODIS," in Earth Observing Systems X, Proc. SPIE 5882, 58820W, (2005).

9. H.R. Gordon and M. Wang, "Retrieval of water-leaving radiance and aerosol optical thickness over the oceans with SeaWiFS - a preliminary algorithm," Appl. Opt. 33, 443-452, (1994).

10. R.A. Barnes, A.W. Holmes, W.L. Barnes, W.E. Esaias, C.R. McClain and T. Svitek, SeaWiFS Prelaunch Radiometric Calibration and Spectral Characterization, NASA Tech. Memo. 104566 23, S.B. Hooker, E.R. Firestone, and J.G. Acker, eds., (NASA Goddard Space Flight Center, Greenbelt, Maryland, 1994).

11. R.E. Eplee, Jr., R.A. Barnes, and F.S. Patt, "Changes to the on-orbit calibration of SeaWiFS," in Algorithm Updates for the Fourth SeaWiFS Data Reprocessing, NASA Tech. Memo. 206892 22, S.B. Hooker and E.R. Firestone, eds., (NASA Goddard Space Flight Center, Greenbelt, Maryland), 12-19, (2003).

12. M. Wang, K.D. Knobelspiesse, and C.R. McClain, "Study of the Sea-Viewing Wide Field-of-View Sensor (SeaWiFS) aerosol optical property data over ocean in combination with the ocean color products," J. Geophys. Res. 110, D10S06, doi:10.1029/2004JD004950, (2005).

13. H. Fukushima, L.-P. Li, and K. Takeno, "Increasing trend in sub-micron aerosol particles over East Asian waters observed in 1998-2004 by Sea Wide Field-of-View Sensor (SeaWiFS)," in Remote Sensing of Clouds and the Atmosphere XI, Proc. SPIE 6362, 636205, (2006). 